\title{
Critical Factors for Success in University-Industry Research Projects
}

Ana M. Bernardos Barbolla* and José R. Casar Corredera

ETSI Telecomunicación, Universidad Politécnica de Madrid, Spain.

\begin{abstract}
This study provides insight into the reality of university-industry technology transfer through the assessment of some of the most influential factors for success or failure in research contracts. This widespread mechanism of technology transfer is examined in the light of exhaustive information and experience gathered from thirty interviews with qualified university researchers. The interviewees, who have been directly involved in collaborative projects with industry partners, have deeply described both sound and unsatisfactory cooperation cases, in order to explore which relevant circumstances have led to success or failure. The analysis drives to conclude that there are some features (beyond technological ones) related to the corporate partner's strategic and functional characteristics, which come to be decisive for success. For example, company’s real interest and involvement during the technology transfer process, its capacity to assimilate new knowledge and a confident attitude towards the university research group are identified to be key elements for attaining an effective technology transfer. In this contribution, the importance of these aspects is contextualized and summarized in a model for successful technology transfer.
\end{abstract}

Keywords: Technology transfer, university-industry collaboration, research projects. 


\section{Introduction}

Among the different types of instruments used to transfer technology from university to industry, collaborative research happens to be an important mechanism in many countries (Meyer-Krahmer and Schmoch 1998). In particular, research contracts are a growing activity at some institutions (Geuna et al. 2003) and, in general, this transfer model works well in Europe (EIRMA 2004), where the $80 \%$ of the Offices of Technology Transfer serve as an interface for managing research contracts (COM 2004). Wright et al. (2008) state that contract research is a knowledge transfer tool which may be more important than intellectual property rights in terms of potential revenues. Bekkers and Bodas Freitas (2008) agree with the previous authors in their comparison of different knowledge transfer mechanisms: they find that collaborative and contract research are considered as important technology transfer tools by professionals working in medium-big firms and very important for researchers, especially when the area of knowledge has an applied component (e.g. computer science). The fact is that, as well as other technology transfer methods (spin-offs, patents, licenses, etc.), research contracts are especially being promoted in universities (Poyago-Theotoky, Beath and Siegel 2001), nowadays committed to the uptake of what has been referred to as their 'third mission' (Etzkowitz 2000) aimed at valuating the publicly financed research outcomes.

In this contribution, university-industry technology transfer is revisited to analyze this specific instrument of collaboration: our objective is to shed some light on the factors or criteria for achieving success in a university-industry relationship carried out through projects organized as research contracts. To achieve our purpose, we accomplished an empirical work based on the analysis of thirty real university-to-industry technology transfer experiences governed by research contracts. To the best of our knowledge, we find that this approach is different and complementary to the studies focused on accomplishing a quantitative analysis based on the measurement of technology transfer outcomes (revenues, patents, etc.), which are not often driven to evaluate contract research.

\footnotetext{
* Correspondence Address: Ana M. Bernardos, E.T.S.I. Telecomunicación, Desp. C.315-1., Ciudad Universitaria, s/n.,
} 
In this point, there are some considerations that should be made to clarify the approach of this contribution. First of all, the study gives insight into the transferor's (university) point of view on the issue, gathered through a firsthand explanation by a selected group of researchers with a noticeable experience in working with the corporate partners. Secondly, as the main objective has been to compare and identify key circumstances that led to success or failure, we initially built a sample of both 'successful' and 'unsuccessful' projects; the researchers were asked to describe one project which was afterwards classified depending on its final result. Finally, the chosen sample of researchers provided us with data that drove us to focus on success or failure factors depending on the companies involved in the technology transfer process.

Summarizing, thirty researchers provided us with an accurate description of one of their projects (which were classified as successful and unsuccessful ones, regarding the selected technology transfer effectiveness criterion, see next Section), discussed what influence certain circumstances had on the result of the technology transfer process and gave their opinion on which obstacles led to the failure of their experiences or underlined what factors notably favored success. The analysis of the gathered information drove us to conclude that success was not clearly defined by a single factor, but for a combination of favorable circumstances. On the other hand, unsuccessful projects were conditioned by determinant facts: from technical difficulties or shortage of funding to lack of definition or relational problems, depending on the project's characteristics.

In the following pages, a brief review of the possible effectiveness criteria to analyse technology transfer processes is firstly done (Section 2), in order to introduce the one used for our analysis. Afterwards, the context and methodology of our empirical approach are detailed (Section 3), just before discussing some significant results (Sections 4 and 5) and presenting a model to summarize our conclusions (Sections 6 and 7).

28040, Madrid, Spain. Email: abernardos@grpss.ssr.upm.es 


\section{Effectiveness criteria and measures of success for technology transfer}

\section{processes.}

In all technology transfer processes, the definition of boundaries and scope is always a complicated task. Nevertheless, it is also essential for assessing whether the interaction is satisfactory or unsuccessful. For our purpose, 'technology transfer' is the process by means of which technology and its associated knowledge, developed in a particular environment by a transfer agent (transferor university), are adapted and applied to another context to support innovation processes, satisfying the requirements of the technology recipient (transferee company).

To date, there are some studies in the literature that have directly or indirectly tackled the analysis of success factors in university-industry technology transfer from different perspectives. For example, Baron (1990), Carr (1992) or Martyniuk, Jain and Stone (2003) analyze the barriers for successful technology transfer. Some proposals aim at measuring success from the level of satisfaction of the stakeholders which take part in the technology transfer process (Wu 1993), while others prefer to do it through the evaluation of the adequacy of the technology result to the transferee' needs or taking into account the compliance of costs and deadlines (Might and Fischer 1985). Spann, Adams and Souder (1995) make a detailed proposal of parameters to measure technology transfer effectiveness, which considers short term factors (such as number of licenses, requests for help, transfer budgets, etc. ) and long term ones (such as cost savings, new commercial sales, new products, royalties, user satisfaction, etc.). Stock and Tatikonda (2000) also propose to consider some socio-technical features (such as satisfaction) or strategic issues (long-term development of professional competences) while evaluating the effectiveness of technology transfer.

Dalziel (1994) explains that the most effective method for transmitting knowledge in a specific area of knowledge (i.e. robotics and intelligent systems) is not acquiring the knowledge but directly accessing the source and building relationships; the receptor capacity to assimilate the knowledge is also a key issue. Boulter and Bendell (2002) state the importance of cultural interfaces 
and correct IP rights management. Rogers, Takegami and Yin (2001) evaluate the technology transfer process as a type of communication which demands skilled personnel, adequate resources and organizational and incentives structures. They measure the effectiveness of technology transfer from 'research universities' by considering the performance in invention disclosures, US patent filed, number of start-up companies and the total amount of technology licensing royalties earned. Siegel et al. (2003) study the impact of Technology Transfer Offices in the success of the process. Cummings and Teng (2003) accomplish a case study which finally relates success to the partners' understanding, to the extent to which the parties share similar knowledge bases and to the frequency and quality of interactions between the transferor and the transferee. Debackere and Veugelers (2005) evaluate how to consolidate industry science links and conclude that incentives and a “decentralized management style” in the Technology Transfer Offices promotes success. Anderson, Daim and Lavoie (2007) design a data envelopment analysis (DEA) to benchmark the technology transfer efficiency in different universities and medical schools. As previously, the model considers as inputs licensing incomes, start-up companies and patents filled and issued. Finally, Phan and Siegel (2006) make a wide review of literature analyzing the effectiveness of university technology transfer from different perspectives (institutional, organizational and individual factors). The authors focus on measuring the effectiveness of licensing and the creation of new businesses.

Bozeman's approach (Bozeman 2000) is especially interesting for the purpose of our research. Elaborating on Carr's work (Carr 1992), Bozeman proposes a technology transfer effectiveness' model which joins together the characteristics of the transferred object (scientific knowledge, physical technology, technology design, process and know-how) and stakeholder features, taking into account the transfer media (open literature, patents, licences, informal absorption, personal exchange, on-site demonstration, spin-offs...) and also considering the peculiarities of the demand environment in which the process is carried out. He defines six effectiveness criteria applicable to technology transfer: 'out-the-door', market impact, economic development, political reward, scientific and technical human capital, and opportunity cost. The 
'out-the-door' criterion, extremely common in practice according to Bozeman, does not imply either assessment of the impact of the transferred technology on any organizational aspect or any concern about whether the technology is put to use. Success is based exclusively on the physical arrival of the transferred asset at the receiving company. The market impact criterion considers the changes in profit or market share induced by the transferred technology. The economic development criterion estimates the consequences for the regional or national economy. Political benefits achieved by the accomplishment of a technology transfer process are included under the political rewards indicator. The opportunity cost criterion accounts for other impacts not considered above. And, finally, the enhancement of human resources skills is taken into account in the scientific and technical human capital criterion. Thus, there are many effectiveness criteria that are highly dependent on the evaluating agent and its interest and can also be determined by the type of transferred object. Accordingly, market impact criteria seem to be more appropriate when the transferred result is close to the final product.

From the review of the literature, it is obvious that there is a wide variety of acceptable criteria for evaluating the process of technology transfer, ranging from the definition of success or failure as just having completed an adequate physical transfer, to others that assess technology transfer success at the level of effective use of the transferred product, process or service, and through its impact in organisational and market terms. As stated by Bozeman's model, the definition of 'effective technology transfer' is ambiguous and dependant on the analysis' context. The difficulty of measuring the effectiveness of technology transfer processes is related to the fact that it is an interorganizational process opened to a great number of different situations. In general, the trend is to use easily measurable indicators to evaluate the impact of technology transfer, irrespective of whether they match the parameters that should ideally be considered.

This paper does not intend to elaborate on or discuss known or new transfer effectiveness criteria, but rather to focus on the identification of the elements that insistently appear in or are absent from successful or failed technology transfer experiences. The measure of success/failure we 
have used is simply whether the technology had or had not been finally adopted (used) or commercialized by the company. This criterion lies between Bozeman's 'out-the-door' and the 'market-impact'. It is important to note that success is not diagnosed by the fact that the technology is packed and formally acknowledged by the company, neither is failure measured in terms of lack of commercial or economic gains. Then, technological sound results do not directly imply to classify the technology transfer project as successful; it is necessary that the outcome is adopted or used by the transferee.

\section{Context and methodology.}

Briefly, this paper intends to improve the understanding of how university groups and technological companies truly face their collaboration; it strives to infer conclusions about success and failure factors, always from the transferor viewpoint (as the study analyzes the university researchers' experience).

To reach our objective, we decided to undertake a sufficient number of carefully selected personal interviews. We expected this method to provide more exhaustive and live information about the technology transfer context than an opinion poll, despite it not being statistically significant. It goes without saying that this somewhat limits the scope and neutrality of some of the results. However, the interviews have been designed and the data used to minimize any potential biases.

The study has been carried out at the Technical University of Madrid, the largest technical university in Spain. As Arvanitis, Kubli and Woerter (2008) state 'science institutions with a stronger orientation to applied research are also stronger inclined to get involved in technology transfer to industry’. In particular, contract research typically involves applied research (PoyagoTheotoky and Siegel 2002). So the analysis ecosystem (a technical university) is a natural environment for contract research. 
In our study, thirty researchers in different areas of knowledge, most of them working in information and communication technologies, were interviewed. All of them had carried out a high number of industrial projects over recent years and sustained many fruitful cooperation agreements with different industrial partners.

So as not to base the study on a mere analysis of opinions aimed at establishing what the interviewees thought about some preliminary hypothesis, the interviews were conducted to collect full information about specific projects performed in collaboration with industrial partners. We wanted to steer clear of reducing success to proof of technological feasibility: a technically good result not put into use or adopted by the transferee company was qualified as unsuccessful or, at least, unsatisfactory. Each researcher was then invited to choose a particular illuminating experience, which was classed as 'successful' or 'unsuccessful' in terms of the effectiveness technology transfer criterion defined for the experiment.

On the one hand, our aim was to collect information about the real circumstances under which the projects were carried out, and on the other, to consider the perception our interviewees had about the determining factors affecting the result of the technology transfer process. Then, the main initial goal was to list a number of factors/characteristics that could provide us with a complete profile of the project to be analysed. Our purpose was neither to classify the features considered, nor to generate a model, although a preliminary classification was chosen for convenience. The transfer process was explored from four perspectives from which we were able to decide on a list of potentially key factors for the outcome of technology transfer (detailed factors are summarized in Table 1):

- Project features. The project was the unit of analysis in this study. General project features as number of stakeholders or funding sources were to be considered. To assess project feasibility, we concentrated on its technical features (Lin and Berg 2001) revealed by the maturity of the technology used and its level of codification (Flannery and Dietrich 2000) complexity and ambiguity (Smilor and Gibson 1991). We also analysed other significant 
issues for the technology transfer progress, such as the clear definition of objectives and milestones (Cooke and Mayes 1996; Ransley and Rogers 1994) and the estimated usefulness of the anticipated result.

- Company involvement. With the aim of finding out how vital the company's involvement in the project was for success in university-industry technology transfer, we examined some criteria related to corporate interest in the process, such as allocation of resources, involvement of suitable corporate professionals capable of assimilating the technology and contributing to project development (Isaacs and Tang 1996; Szakonyi, 1990), and management support and corporate receptiveness and learning ability (Lynskey 1999).

- Core competency and motivation of the university. From the view of the university, both researchers' experience in the core technologies of the project and their motivation and attitude towards collaboration with industry (Smilor and Gibson, 1991; Wolff 1989) were identified as essential for explaining a successful technology transfer process.

- Relationship among players. Cultural differences seemed to be a real problem for smooth and effective technology transfer management (Lin and Berg 2001; Smilor and Gibson 1991). As a derivative, mutual trust (Bennett 1996; Jassawalla and Sashittal 1998; Lin and Berg 2001; Santoro and Saparito 2003), milestones achievement, good coordination mechanisms and, in short, a good understanding between working teams (Siegel et al. 2004) were also considered fundamental for the outcome of technology transfer.

\section{[TABLE 1 ABOUT HERE]}

With this four-angle view in mind, and the support on the existing literature, we elaborated the interview guideline. It was finally divided into two clearly separate parts. The purpose of the first part (see Appendix for an excerpt of the guideline) was to retrieve some project information that might be relevant for describing the context of the technology transfer process (the project objectives, its duration, stakeholders, funding sources, the desired outcome at the beginning of the project, its expected use by the company, the final result, its real final place in the value chain, the 
interaction method, etc.). Once the background of the transfer process had been reviewed, the second part of the interview focused on determining what appeared to be the most important factors for making the project succeed or causing it to fail. Researchers were asked to freely indicate which aspects were decisive in their view for success or failure, and to rank the above-mentioned depending on their relevance for the process, in order to contrast reality and opinions.

In the next section, we present a brief outline of the examined projects and a preview of the influence of the different factors on the success or failure of university-industry technology transfer.

\section{Summary of results.}

\subsection{Describing the projects: an analysis of basic features.}

To get an overview of the projects under analysis, we firstly asked the interviewees about some of the general characteristics of their projects. Figure 1 shows, both for successful and unsuccessful experiences, the percentage of cases in which the different features were present in the project. Analysing Figure 1, it is possible to group some conclusions regarding three aspects of the collaboration: Composition and funding of the partnership, Project innovation degree and Stakeholders experience.

\section{[FIGURE 1 ABOUT HERE]}

\section{Composition and funding of the partnership.}

In most successful experiences, the partnership was composed of a single university group and a company only; no other participants were directly involved in the projects. Not surprisingly, the results reveal that a bilateral relationship appears to improve the process, as coordination, organization and, ultimately, success becomes more difficult the more participants there are.

With respect to financing, one sign of the enterprise's interest in the project could be partly traced to the allocation of its own resources. The allocation of significant own funds to the project increases company awareness of its role. Of course, we do not intend to generalise this remark but, according to the results (quite a few subsidised projects are in the case of successful transfer), full or 
significant financial support on the company side correlates with a better attitude towards collaboration.

\section{Project innovation degree.}

In our study, most successful technology transfer projects were aimed at enhancing existing products. This goal probably favoured the establishment of clearer objectives, which made understanding between partners easier. In most of these cases, the company had extensive prior knowledge of the project issues and was capable of evaluating hitches and transmitting its objectives to its collaborators. It seems that, generally, unsuccessful projects intended to be more innovative (at least, regarding strategy, organization and market), as their purpose was, in more than half of the cases, to open a new business line.

The objective in most of the successful transfer projects examined (60\%) was to develop a nearly ready-to-use product or process; whereas $80 \%$ of unsuccessful projects were aimed at getting a result that had to be integrated into a more complex system. This may be related to the fact that integration processes are usually tricky to accomplish, as they require the assembly of multiple components that then need a lot of coordination that is difficult to achieve.

In most unsuccessful projects there were changes in terms of objectives and methodology or chosen technical approach, perhaps because failed experiences had a less precise general definition. Methodological or technical amendments can be linked to several factors, such as institutional preferences for a particular technology or the unpredictable need to adapt systems already in place, proposed or imposed by collaborators or clients. Moreover, we can say that adjustments during project development are not a sign of irremediable failure. On the contrary, changes appear not to be unusual in some sorts of successful technological development projects.

\section{Stakeholders experience.}

In successful projects, all the involved companies were used to work with universities. In our sample of unsuccessful projects, the collaboration rate was lower but also remained high. Specifically, most professionals directly involved in the technology transfer process had had 
previous relationships with the university. On the other hand, the collected data show that a higher percentage of university research groups taking part in successful projects knew their partners from previous collaborations than their colleagues describing unsuccessful experiences. In fact, a significant group of researchers claimed that their relationship with the transferee company had begun a long time ago.

\subsection{Determining the causes for success and failure: a comparison of cases.}

To complement this summary of general data, participants were asked to score the presence of some project features on a scale of 1 (minimum) to 5 (maximum). An analysis of the results shows that there were remarkable differences between the score of some features in successful and unsuccessful projects, thus giving insight into what circumstances came to be relevant for technology transfer success.

Figure 2 shows a comparison of these differences, as the percentage of researchers that identified the analyzed factors as clearly present in their technology transfer process. Although it is not possible to infer any concluding statement, the figure illustrates that some circumstances were clearly present in successful projects when comparing them against unsuccessful experiences (achieving both a high percentage of maximal score and a high difference between averages of 'presence').

\section{[FIGURE 2 ABOUT HERE]}

There are three factors attaining the highest scores (both in percentage and difference of averages), two of them related to company attitude and the other, to technological feasibility.

- Company-related features. There are a number of factors related to corporate features and company attitude towards the cooperation that certainly make the difference between successful and unsuccessful technology transfer experiences. These factors may be identified from Figure 2, just selecting those mentioned by around $50 \%$ of the interviewees that described successful projects, and afterwards picking among them those that surpass the 0.5 threshold in terms of difference 
between averages. Management support and the company team's interest in assimilating the obtained results outstand in terms of difference between successful and unsuccessful projects. Corporate interest, although separately evaluated in our analysis, is directly linked to many of the other factors. Features related to the relationship among corporate and university working groups are ranked next. Coordination (clearly higher in the case of successful projects), milestones fulfilment and the quality of the relationship surpass the 0.5 threshold and are pointed by more than $50 \%$ of the interviewees describing successful projects.

Therefore, from these and other differences in resources allocation, communication within the company group, project monitoring or company confidence both in the research group and in the project results, we can sketch a picture (Figure 3) to show that inexistence of real corporate interest is a conclusive circumstance that often explains, or at least contributes to explain, success or failure of a given research project.

\section{[FIGURE 3 ABOUT HERE]}

- Technology-related features. The analysis of technology-related features shows that, on average, the technical risk of successful projects was lower and, consequently, their technical feasibility higher. In both cases, technologies in use were considered very mature by a small percentage of the interviewees; the average maturity rate of technology was similar in successful and unsuccessful developments. Project failure was governed by technical factors in most cases. Nevertheless, it should be noted that in our work, technology transfer failure included unsuccessful projects achieving good technical results that, for a variety of reasons, were not corporately assimilated afterwards.

In Figure 2, we can also notice the existence of two factors presenting a high score in percentage and with a difference in average close to zero: in both successful and unsuccessful projects, the knowledge the university research group had of the technology used for the project and their motivation to transfer the result was similar and high. This result can be a consequence to the 
chosen sample (university researchers); although surely influential, these two factors do not seem to determine the result of the technology transfer.

In a nutshell, considering extreme scores and averages, all the interviewees describing successful projects stated that their experiences were characterised by significant technical feasibility, a noticeable interest in assimilating the project results on the company side and a strong motivation to carry out the technology transfer on the part of the university. For almost all satisfactory projects, they remarked upon the good relationship within the team, and that both the number and ability of its members were adequate. The level of general knowledge required by the university group to carry out the project was high and so was its member's flexibility to adapt to changes in timing or methods. Moreover, both industry and university were satisfied with milestones achievement and deadlines compliance by the other partner. Coordination among stakeholders was also outstanding, as was the university's satisfaction with the company's project monitoring activities. As shown, a conjunction of numerous favourable circumstances occurred in successful projects.

All the researchers that described unsuccessful projects stated that their groups had a high command of the general knowledge required as well. They also pointed out that the university was highly motivated to transfer the project results. Good acceptance of changes in methodology or deadlines was also remarked upon by most interviewees (86.7\%). More than three quarters of interviewees (80\%) declared that the university actively participated in the project definition phase, and that the company's confidence in the research group was high. On the other hand, more than half of the interviewees considered the allocation of human resources to the project to be insufficient and also said the same about material resources (40\%). Almost one-third of researchers remarked upon their projects having technical difficulties, and working teams not being coordinated. The same percentage complained about the inadequate qualifications of professionals assigned to the project. 


\section{Key factors for industry-technology transfer success: the researchers' opinion.}

In the second part of the interview, researchers were asked to identify and score a number of factors that, under their point of view, had influenced the technology transfer process. Contrary to the previous Section, these questions focused on showing not the reality, but the researchers' personal opinion about how the technology transfer had developed. The results are summarized in Table 2 and discussed below.

\section{[TABLE 2 ABOUT HERE]}

A considerable number of researchers found the high real project usefulness a conclusive factor for success. On the contrary, low real project usefulness was not stated repeatedly when describing an unsuccessful project. This lack of causality between a positive factor and the equivalent negative one was often noticed. In the end, successful technology transfer processes were developed under a singular combination of constructive factors, whereas unsatisfactory experiences were generally conditioned by a single unfavourable circumstance.

Data extracted from a correlation matrix analysis give some hints about the dependencies among factors. For example, corporate confidence in the project is mainly linked to the perception of technical feasibility (0.86), allocation of material resources (0.76), adequacy of the corporate personnel assigned to the project $(0.75)$ or confidence in the research group (0.71). Company capacity to put the results into use seems to be related to management support to the project $(0.76)$ or to the usefulness the project has for the company (0.76).

Apart from these considerations, the main results were about:

- Technical feasibility. Low feasibility and realism of the proposed project, reinforced by high technical risk, are two of the most relevant factors that can lead to technology transfer failure. In the course of the experiment, we easily identified two different types of unsuccessful projects: projects that did not achieve a technically sound result, and projects whose technical aims were attained but not incorporated, assimilated or used by the client company. Although a high percentage of unsuccessful projects achieved technical sound results, there were other factors 
that lead to failure in at least half of the unsuccessful projects. Regarding technology maturity, more than $50 \%$ of the interviewees remarked in successful projects upon the use of mature core technologies. A quarter of researchers mentioned that the opposite happened in unsuccessful projects.

- Project usefulness (for the company). Transferee awareness of the usefulness of the result and its impact on the corporate technological strategy shapes a better attitude for dynamically defining requirements and collaborating in problem solving, as noted by $80 \%$ of the interviewees. In fact, a significant number of unsuccessful examples were influenced by the lack of a clear definition of objectives at the beginning of the project. This affected both the projects that had technology-based problems and the ones that failed due to the corporate assimilation of the result. On the other hand, some researchers mentioned that not enough corporate human resources being assigned to the project and their professional inadequacy were significant factors for failure.

- Corporate capacity to assimilate the result. Company capacity to integrate the final result into the value chain appears as another relevant factor. Actually, more than $25 \%$ of the interviewees mentioned a clear inability to use the generated results as a decisive cause of technology transfer failure. The adequacy of the corporate team following the project was pointed as crucial for success.

- Confidence and experience. The significance of coordination between the two groups was outlined by more than half of the participants that reported satisfactory projects (53\%). Another noteworthy factor for success seems to be the company's confidence when success was achieved, three quarts of the researchers that stated high levels of corporate confidence both in the research group and in the project's results, considered these characteristics as very relevant for achieving a sound technology transfer. Nevertheless, most of the researchers that described unsuccessful projects (80\%) were also highly trusted. Company team inexperience in collaborating with the university was a complication in some cases. 
From Table 2 it is possible to infer that successful technology transfer processes were developed under a singular combination of constructive factors (a bundle of favourable characteristics brought the projects into success), whereas unsatisfactory experiences were generally conditioned by a single unfavourable circumstance. There are some factors that are predominantly important in unsatisfactory projects that are on the contrary considered as irrelevant in successful technology transfer projects. For example, resources allocation remains a residual factor for those that were satisfied with the assignment they got and a key factor of failure for those that had to handle shoestring resources. The same applies to factors like technical risk, definition of objectives, corporate team experience in collaborating with universities, inadequacy or changes in the transferee team or material resources allocation. Most of these factors that researchers that described an unsuccessful project pointed out as key for failure were not so important for researchers that had had successful experiences, basically because their reality was favourable on all these points.

\section{Discussion: towards a model for success.}

From the data presented above, it seems that most successful partnerships keep their projects simple, clearly defining the scope and each partner's mission at the beginning of the project. A project involving numerous stakeholders usually has more hitches in the course of its development (more than half of the interviewees that described a project with many partners noted that the internal relationship did not work) due to divergent objectives, group heterogeneity and managerial difficulties. If the technological developments are highly linked one to other, poor compliance or failure to achieve the objectives assigned to a particular member can led the project to failure. According to the interviewed researchers, strong leadership is crucial in these cases.

Financing is another key point: significant corporate contribution is usually linked with a higher awareness of project needs and correlated with the interest in its result. The collected data show lower success rates for subsidised projects. 
The reasons for failure put forward by the researchers describing unsuccessful projects ranged from lack of clear compromise regarding product commercialisation on the part of the company to doubtful cost-effectiveness analysis. They also included the corporate inability to put the result into use, some last-minute strategic changes (in terms of technology, commercialisation or management), inexistence of a viable production plan or difficulties in adapting the final product to customer requirements. The main problems that came up in unsuccessful projects were generally related to an unsuitable corporate team, lack of coordination among participants, technical difficulties, and scarce resources allocation. In any case, interviewees especially underlined the importance of technical difficulties, a shortage of funding or inadequate human resources and unclear project definitions, as triggering factors of the failed result. In situations where a satisfactory result was not achieved, low feasibility and realism of the established objectives due to technology immaturity and high technical risk were the most often mentioned factors, together with a shortage of technological knowledge on the research group side.

Not surprisingly, it can be confirmed that satisfactory technology transfer processes are not due to there being a single favourable factor; it is rather the combination of a bundle of positive circumstances that leads the project to succeed out. Researchers did not identify a particular cause for success: successful projects were described in twenty-one features; fourteen of them were considered very important or important for the success of technology transfer (67\%). Of these factors, interest on the company side both in its result and during the project development stage, and high motivation and good command of the necessary knowledge to undertake the project on the university group side stand out as significant for success. According to our data, 'corporate appraisal of the project as highly useful in practice', 'company confidence in the university group' and 'the corporate team's interest in assimilating the project outcomes were conclusive for success.

On the other hand, failure is normally associated with a particular factor related to technical or organizational obstacles. During the study, the interviewees especially underlined the importance of technical difficulties, shortage of funding or inadequate human resources and unclear project 
definition, as triggering factors of failure. In situations where a sound technical result was not achieved, low feasibility and realism of the established objectives due to technology immaturity and high technical risk were the most often mentioned factors, together with a shortage of technological knowledge on the research group side. Commonly, if technical problems were present in the course of the project, they were assumed as the main reason for failure, relegating other facts to residual.

Where collaboration led to technical sound result non-assimilated afterwards, influential factors had to do with corporate inability to cope with the transfer process and fundamentally with corporate slovenliness and lack of strategic interest in putting the result into use. Concerning this issue, the reasons for failure put forward by the researchers describing unsuccessful projects went through the lack of clear compromise regarding product commercialisation, doubtful costeffectiveness analysis, inexistence of a viable production plan or difficulties in adapting the final product to customer requirements. Anyway, both unrealistic technical and managerial forecasting were mentioned as generators of a serious misunderstanding among partners, as they usually led to an unviable project design.

\section{[FIGURE 4 ABOUT HERE]}

Summarizing all these statements, Figure 4 shows a model for successful technology transfer. Besides technological aspects, it is possible to identify three general characteristics of the company that influence the result of a particular collaboration with the university. Firstly, the corporate perception of usefulness of the project, which appears to be key element when regarding issues like the adequate allocation of material and human resources. Secondly, the capacity of the company to integrate the results in its value chain, in order to achieve success from the point of view of the put to use of the result. Finally, the company confidence related to the university team and the project's results, linking to experience and good understanding among the partners involved. 


\section{Concluding remarks.}

This contribution presents an analysis of cases aimed at clarifying the success factors in a contractbased technology transfer process. A particular criterion of effectiveness for technology transfer helps to define the concept of 'success' for our purpose: with the aim of not considering technology transfer as the movement of a physical result, we have chosen to assimilate success to usage of the achieved outcome in the transferee company, irrespective of its commercial success.

By starting to examine thirty real experiences of technology transfer, directly explained by the researchers involved, we have classified and analysed the circumstances that favoured or hindered the technology transfer process, which have finally been summarized in a model for technology transfer presented in the previous section. The model shows that some features (beyond technological ones) related to the corporate partner's strategic and functional characteristics, come to be decisive for success. For example, company's real perception of the project usefulness, its interest and involvement during the technology transfer process, its capacity to assimilate new knowledge and a confident attitude towards the university research group are identified to be key elements for attaining an effective technology transfer.

Most projects configuring the empirical sample were in the area of information and communication technologies and were carried out at a technical university. This circumstance conditions the characteristics of the study: both the type of university (with a strong orientation to applied research) and the above-mentioned field of knowledge are prone to collaboration with the industrial agents. Readers may certainly wonder about how representative the chosen sample, actually reduced to groups with proven experience in specific areas of knowledge, is. We feel that, because of the restriction imposed by a limited environment (in organizational and knowledge terms), we cannot affirm that the results will be the same for all experiences in other contexts in which stakeholders' knowledge and culture may differ notably. We provisionally claim, however, that if the basic conditions are met, i.e. groups experienced in collaborating with industry and 
technology-based receiving companies, the conclusions stated above are likely to be reasonably extrapolated, inasmuch as they do not appear to depend on the area of knowledge or on the institutional context.

\section{Acknowledgements}

The authors wish to thank the interviewed researchers for their time and patience in transmitting us their valuable experiences.

\section{References}

Anderson, T.R., Daim, T.U., Lavoie, F. 2007. Measuring the efficiency of university technology transfer. Technovation 27, 306-318.

Arvanitis, S., Kubli, U., Woerter, M. 2008. University-industry knowledge and technology transfer in Switzerland: What university scientists think about co-operation with private enterprises. Research Policy, in press.

Baron, S. 1990. Overcoming barriers to technology transfer. Research Technology Management 33, 1:38-43.

Bekkers, R., Bodas Freitas, I.M. 2008. Analysing knowledge transfer channels between universities and industry: To what degree do sectors also matter? Research Policy, in press.

Bennett, J.L. 1996. Building relationships for technology transfer. Communications of the ACM 39, no. 9:35-37.

Boulter, L., Bendell, T. 2002. Managing the technology transfer process. Proceedings of the IEEE International Engineering Management Conference 2002. Vol. 2, 643-648.

Bozeman, B. 2000. Technology transfer and public policy: a review of research and theory. Research Policy 29:627-655.

Carr, R.K. 1992. Menu of best practices in technology transfer (part 2). Journal of Technology Transfer. Vol. 17, 24-33. 
COM, 2004. Technology Transfer Institutions in Europe. An overview. European Commission. http://europa.eu.int/comm/enterprise/enterprise_policy/competitiveness/doc/tti_typology.pdf.

Cooke, Ian, and Paul Mayes. 1996. Introduction to innovation and technology transfer. Norwood, MA: Artech House Publishers.

Cummings, J.L., Teng, B-S. 2003. Transferring R\&D knowledge: the key factors affecting knowledge transfer success. J. Eng. Technol. Management, 20: 39-68.

Dalziel, M. 1994. Effective university-industry technology transfer. Proceedings of the Canadian Conference on Electrical and Computer Engineering. Vol.2, 743-746.

EIRMA, 2004. Effective collaborative $R \& D$ and knowledge transfer. Conference Report. http://www.eirma.org/pubs/reports/sc-2004-01.pdf.

Etzkowitz, H. 2000. Tech transfer, incubators probed at Triple Helix III. Research Technology Management 43, 6:4-5.

Flannery, W.T., Dietrich, G. 2000. Technology transfer in a complex environment: exploring key relationships. Proceedings of the IEEE Engineering Management Society Conference 2000, 528533.

Geuna, A., Llerena, P., Matt, M., Savona, M. 2003. Collaboration between a research university and firms and other institutions, SPRU Electronic Working Paper Series, no. 108.

Isaacs, E.A., Tang, J.C. 1996. Technology transfer: so much research, so few good products. Communications of ACM 39, no. 9:23-25.

Jassawalla, A.R., Sashittal, H.C. 1998. Accelerating technology transfer: thinking about organizational pronioa. Journal of Engineering and Technology Management 15:153-177.

Lin, B.W., Berg, D. 2001. Effects of cultural difference on technology transfer projects: an empirical study of Taiwanese manufacturing companies. International Journal of Project Management 19:287-293. 
Lynskey, M.J. 1999. The transfer of resources and competencies for developing technical capabilities - The case of Fujitsu-ICL. Technology Analysis \& Strategic Management 11, no. 3:317-336.

Martyniuk, A.O., Jain, K.J., Stone, H.J. 2003. Critical success factors and barriers to technology transfer: case studies and implications. International Journal of Technology Transfer and Commercialisation 2, no. 3: 306-327.

Meyer-Krahmer, F.; Schmoch, U. 1998. Science-based technologies: university-industry interactions in four fields, Research Policy 27: 835-851.

Might, R.J.; Fischer, W.A. 1985. The role of structural factors in determining project management success. IEEE Transactions on Engineering Management 32:71-7.

Phan, P.H., Siegel, D.S. 2006. The effectiveness of university technology transfer. Foundations and Trends in Entrepreneurship, Vol. 2, No. 2: 77-144.

Poyago-Theotoky, J., Beath, J., Siegel, D. 2002. Universities and fundamental research: reflections on the growth of university-industry partnerships. Oxford Review of Economic Policy 18 (1), 10 21.

Ransley, D.L., Rogers J.L. 1994. A consensus on best R\&D practices. Research Technology Management 37, no. 2:19-26.

Rogers, E.M., Takegami, S., Yin, J. 2001. Lessons learned about technology transfer. Technovation $21: 253-261$.

Santoro, M.D., Saparito, P.A. 2003. The firm’s trust in its university partner as a key mediator in advancing knowledge and new technologies. IEEE Transactions on Engineering Management 50, no. 3:362-373.

Siegel, D.S., Waldman, D.A., Atwater, L.E., Link, A.N. 2003. Commercial knowledge transfers from universities to firms: improving the effectiveness of university-industry collaboration. Journal of High Technology Management Research 14:111-133. 
Siegel, D.S., Waldman, D.A., Atwater, L.E., Link, A.N. 2004. Toward a model of effective transfer of scientific knowledge from academicians to practitioners: a qualitative evidence from the commercialisation of university technology. Journal of Engineering and Technology Management 21, Is. 1-2:115-142.

Smilor, R.W., Gibson, D.V. 1991. Accelerating technology transfer in R\&D consortia. Research Technology Management 34, no. 1:44-49.

Spann, M.S., Adams, M., Souder, W.E. 1995. Measures of technology transfer effectiveness: key dimensions and differences in their use by sponsors, developers and adopters. IEEE Transactions on Engineering Management. 42, no. 1:19-29.

Stock, G.N., Tatikonda, M.V. 2000. A typology of project-level technology transfer processes. Journal of Operations Management 18, 719-137.

Szakonyi, R. 1990. 101 Tips for managing R\&D more effectively - I. Research Technology Management 33, no. 4:31-36.

Wolff, M.F., 1989. Technology transfer: a GM manager's strategy. Research Technology Management 32, 5:9-10.

Wright, M., Clarysse, B., Lockett, A., Knockaert, M. 2008. Mid-range universties’ linkages with industry: Knowledge types and the role of intermediaries. Research Policy 37: 1205-1223.

Wu, F.S. 1993. University-industry technology transfer: an empirical study of the industrial firm' organizational practices. PhD dissertation, Rensselaer Polytechnic Institute, Troy, Nueva York.

\section{Appendix}

[TABLE 3 ABOUT HERE] 
Table 1. Factors considered in the analysis of the technology transfer process.

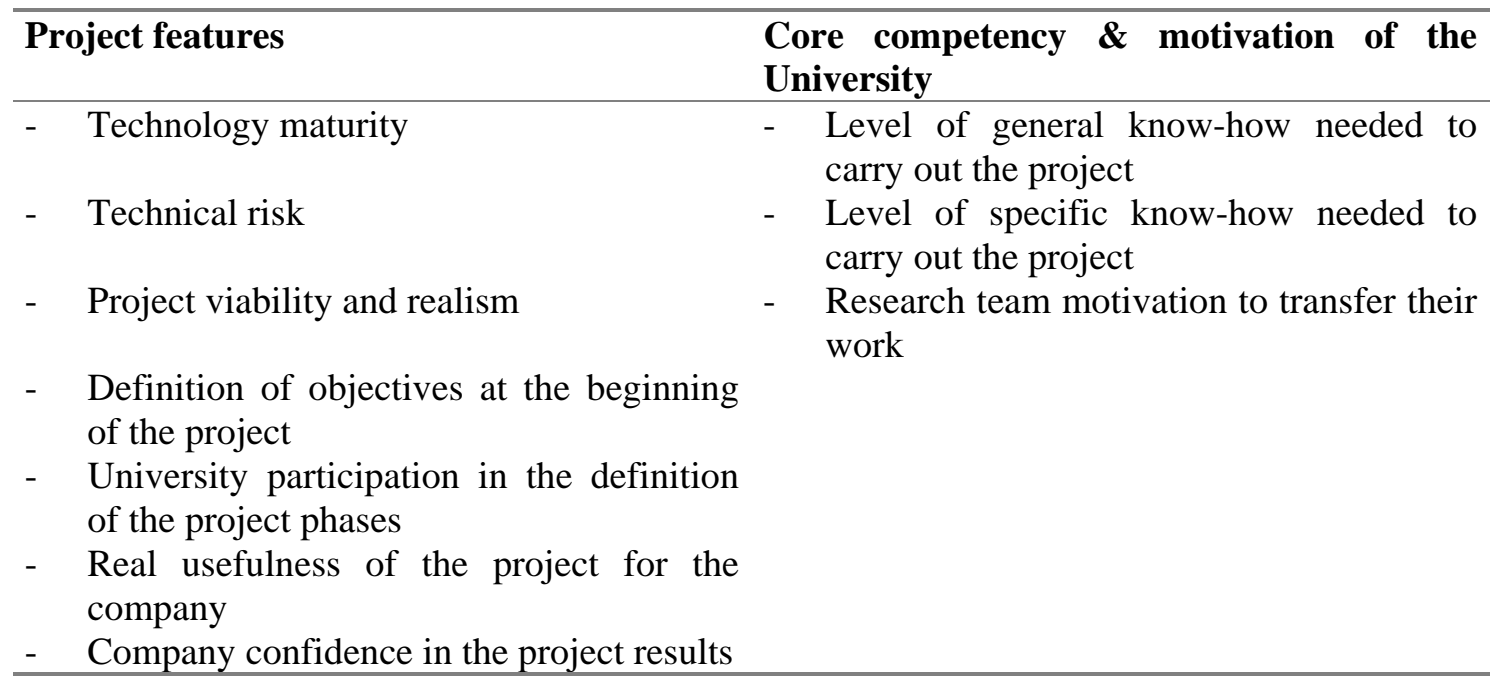

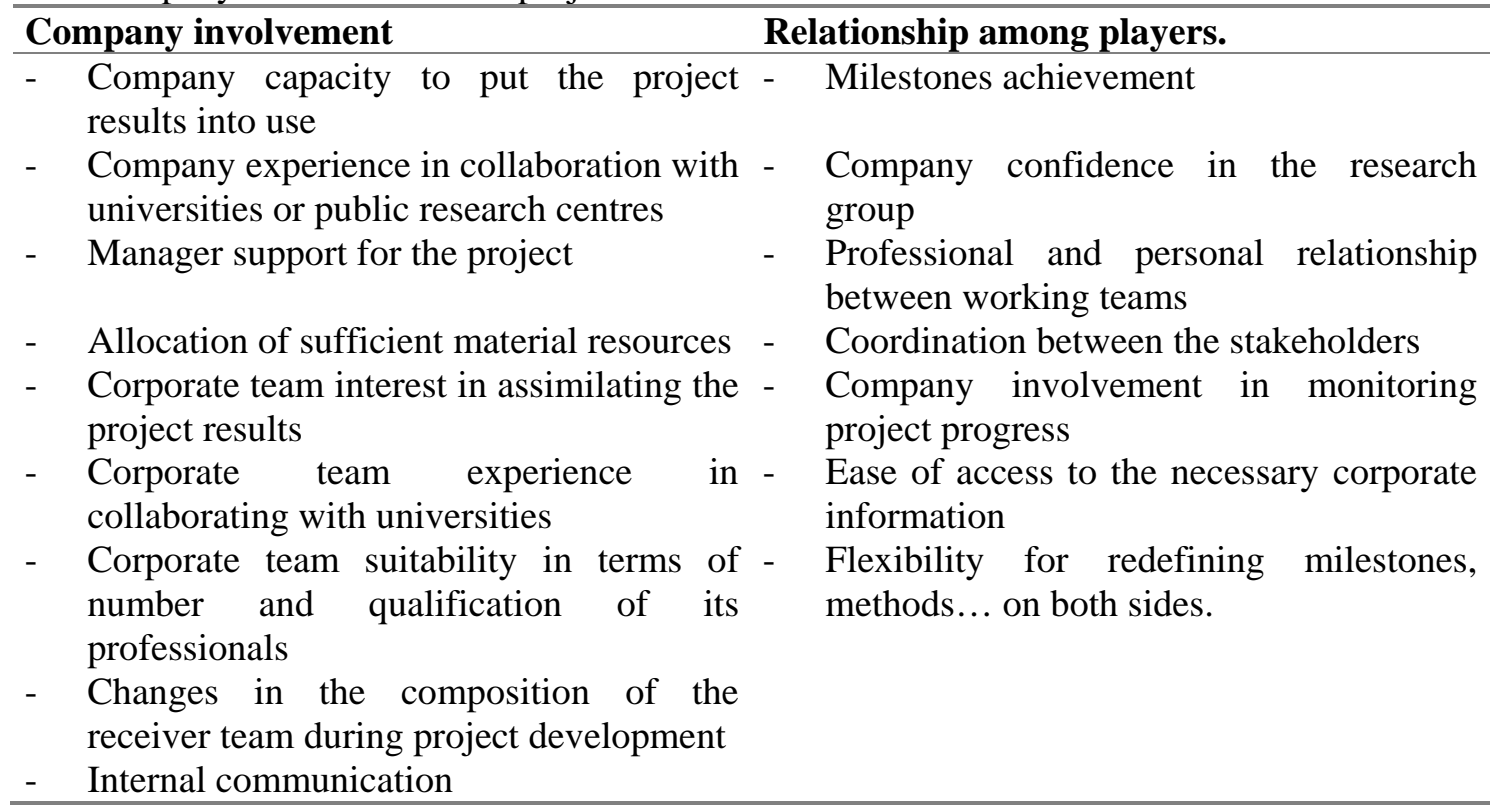




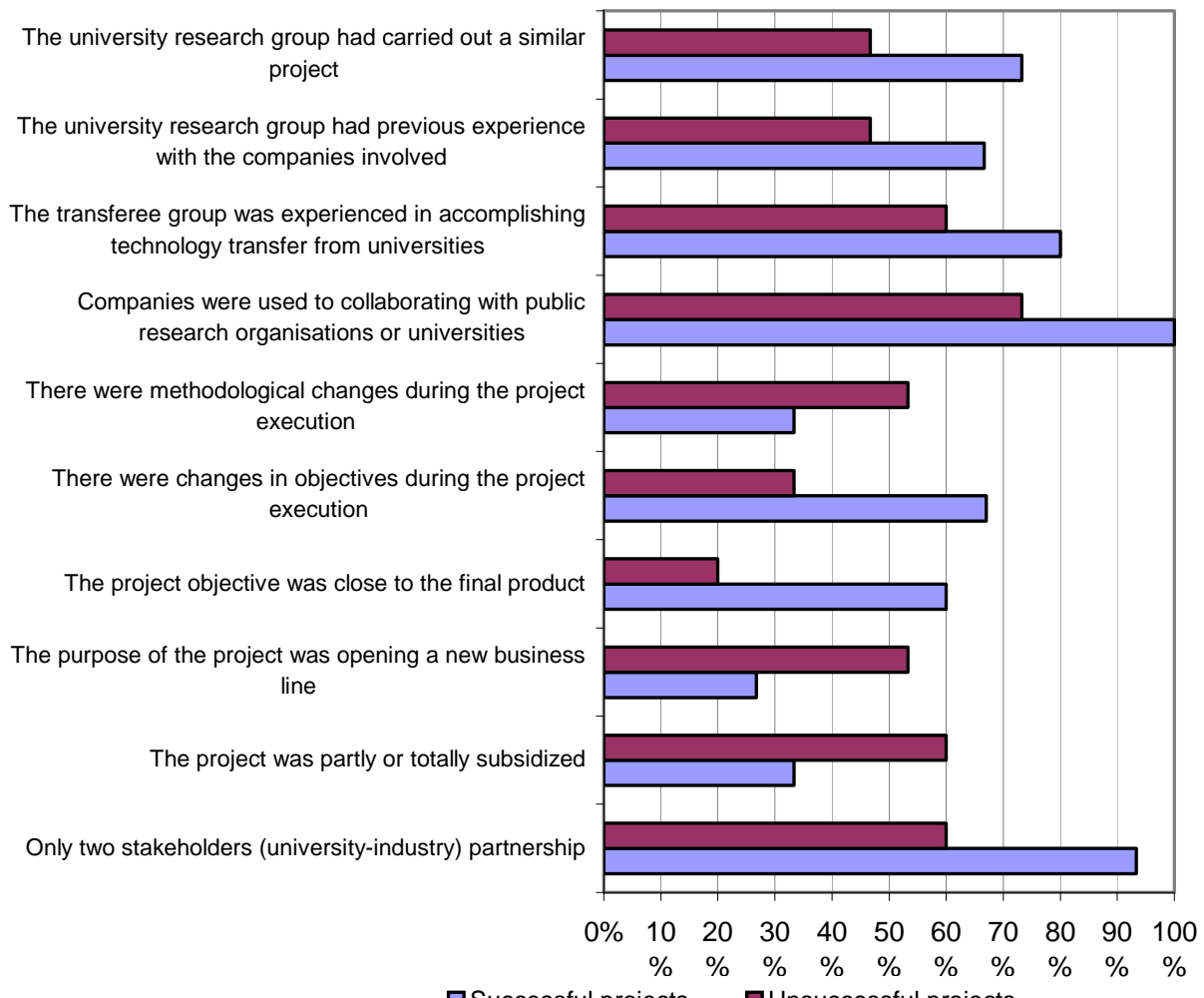

口Successful projects $\quad$ UUnsuccessful projects

Figure 1. A comparison of basic project's features for successful and unsuccessful technology transfer (percentage of cases). 


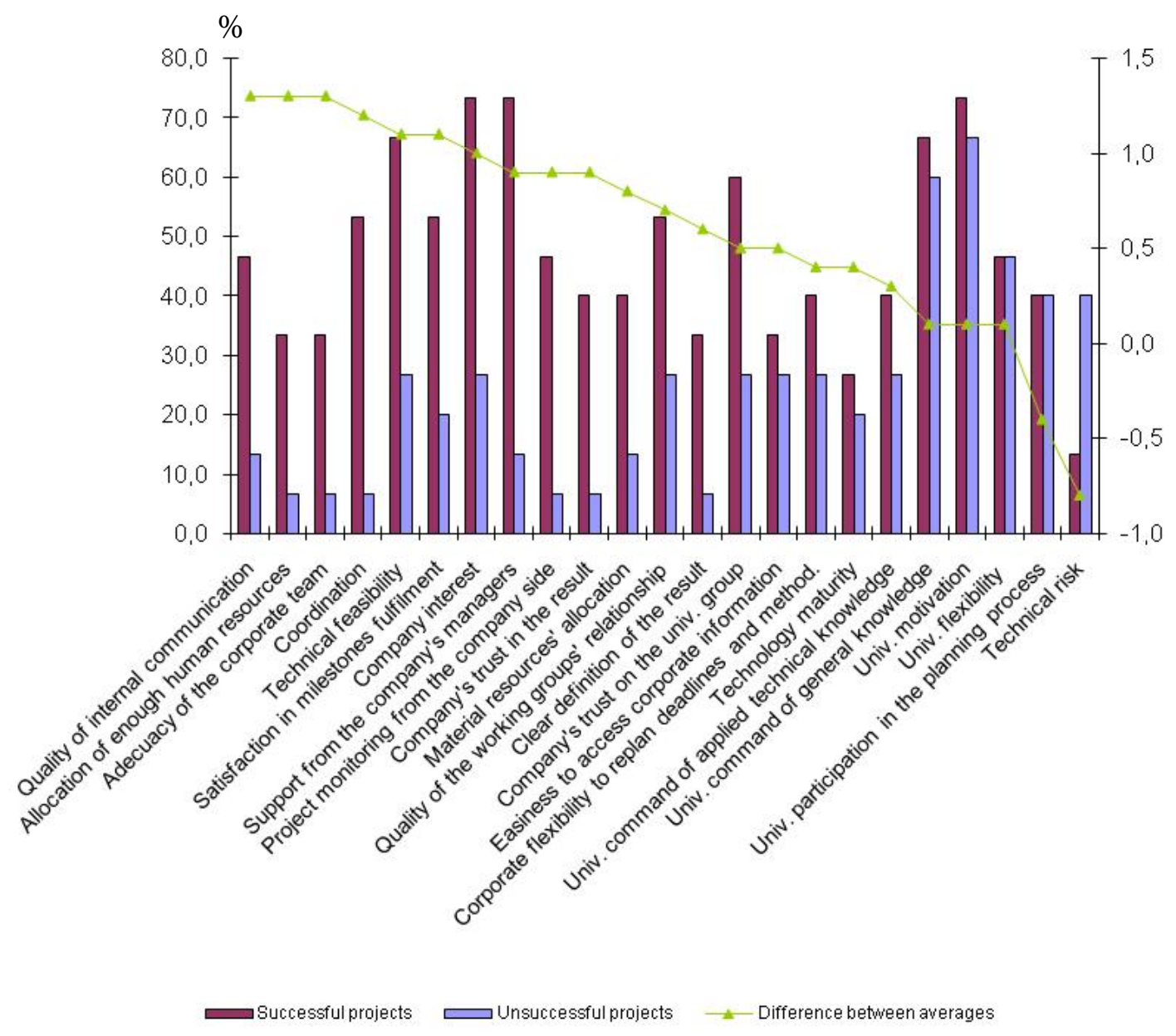

Figure 2. Percentage or researchers that awarded the top score (5) to the relevance of the proposed project features. The line represents the 'difference of average' between successful and unsuccessful projects, for each factor considered. 


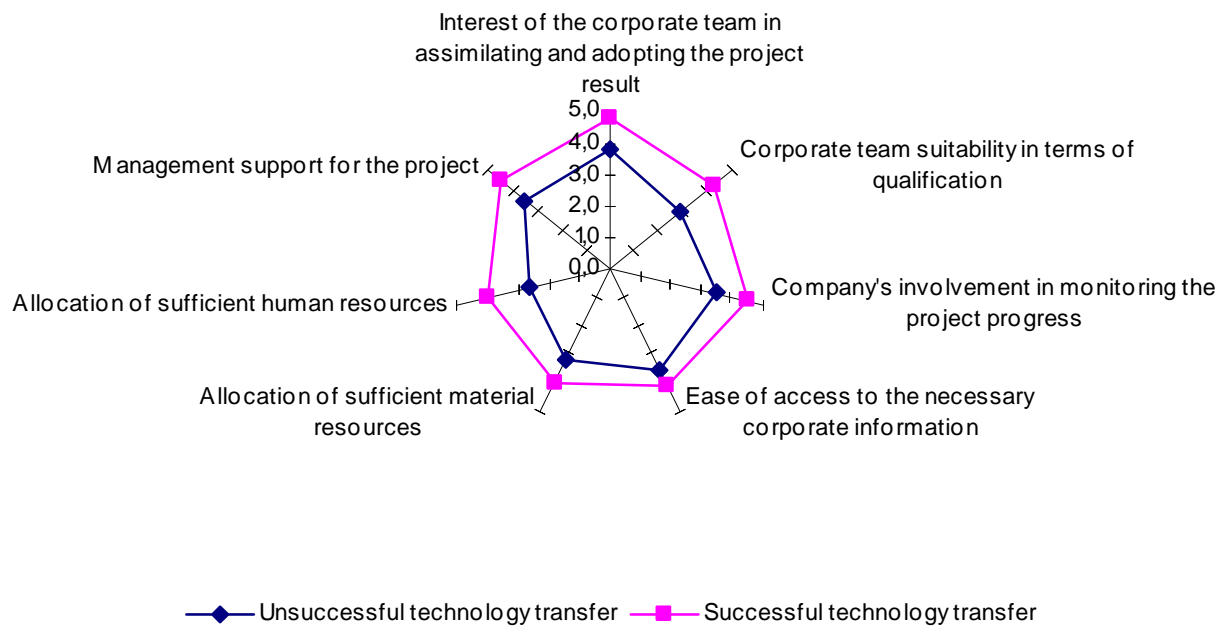

Figure 3. Features related to company's interest (average score, from 1 to 5). 
Table 2. Percentage of interviewees that considered the proposed factors as really conclusive (achieving the highest score) for the result of technology transfer.

\begin{tabular}{|c|c|c|c|}
\hline \multicolumn{2}{|c|}{ UNSUCCESSFUL PROJECTS } & \multicolumn{2}{|c|}{ SUCCESSFUL PROJECTS } \\
\hline$\%$ & Factor & $\%$ & Factor \\
\hline 53.33 & $\begin{array}{l}\text { Low feasibility and realism of the } \\
\text { project }\end{array}$ & 80.00 & High real project usefulness \\
\hline 40.00 & High technical risk & 73.33 & $\begin{array}{l}\text { High company confidence in the } \\
\text { university team }\end{array}$ \\
\hline 26.67 & Loosely stated initial objectives & 66.67 & $\begin{array}{l}\text { Evident corporate team interest in } \\
\text { assimilating project result }\end{array}$ \\
\hline 26.67 & Use of immature technologies & 60.00 & $\begin{array}{l}\text { High corporate capacity to put the } \\
\text { results into use }\end{array}$ \\
\hline 26.67 & $\begin{array}{l}\text { Low corporate capacity to put the } \\
\text { results into use }\end{array}$ & 60.00 & $\begin{array}{l}\text { Good understanding between working } \\
\text { teams }\end{array}$ \\
\hline 20.00 & 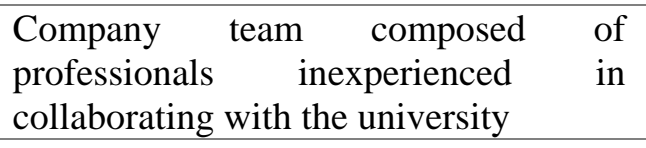 & 53.33 & $\begin{array}{l}\text { Use of mature technologies or } \\
\text { knowledge }\end{array}$ \\
\hline 20.00 & $\begin{array}{l}\text { Allocation of insufficient material } \\
\text { resources }\end{array}$ & 53.33 & $\begin{array}{l}\text { Corporate team composed of sufficient } \\
\text { qualified professionals }\end{array}$ \\
\hline 13.33 & $\begin{array}{lcr}\begin{array}{l}\text { Corporate } \\
\text { insufficient } \\
\text { professionals }\end{array} & \text { and } & \text { composed of } \\
\text { unqualified }\end{array}$ & 53.33 & Company confidence in project' results \\
\hline 13.33 & $\begin{array}{l}\text { Corporate team variations throughout } \\
\text { project development }\end{array}$ & 53.33 & $\begin{array}{l}\text { Good coordination between working } \\
\text { teams }\end{array}$ \\
\hline
\end{tabular}


- Low feasibility and realism for the project

- High technical risk

- Use of immature technologies

\section{OR}

- Loosely stated initial objectives

- Allocation of insufficient material resources

- Corporate team composed of insufficient and unqualified professionals

\section{OR}

- Low corporate capacity to put the results into use

\section{OR}

- Corporate team composed of professionals inexperienced in collaborating with the university

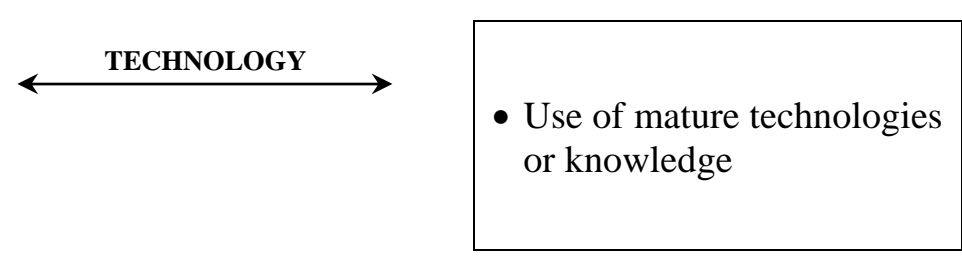

AND
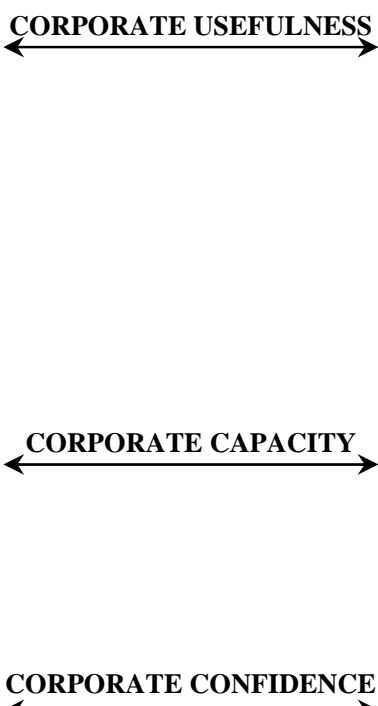

- High real project usefulness

- Evident corporate team interest in assimilating project results

- Corporate team composed of sufficient qualified professionals

AND

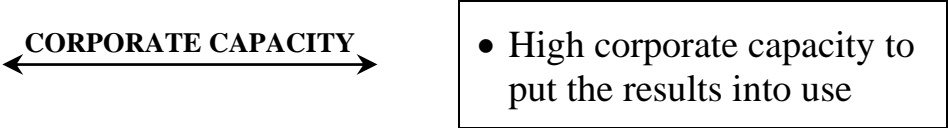

AND

- High company confidence in the university team

- High company confidence in project' results

- Good understanding between working teams<smiles>C1CCC1</smiles>

FAILURE

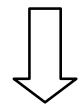

SUCCESS

Figure 4. Towards a model for success: an aggregation of the most determinant features for sound technology transfer. 
Table 3. Excerpt of the first part of the interview guideline, aimed at gathering a detailed description of the circumstances under which a research project was carried out. The complete interview was composed by seventy three questions, designed to analyze both the occurrence of a set of situations and the researcher's point of view on the factors that determined success or failure.

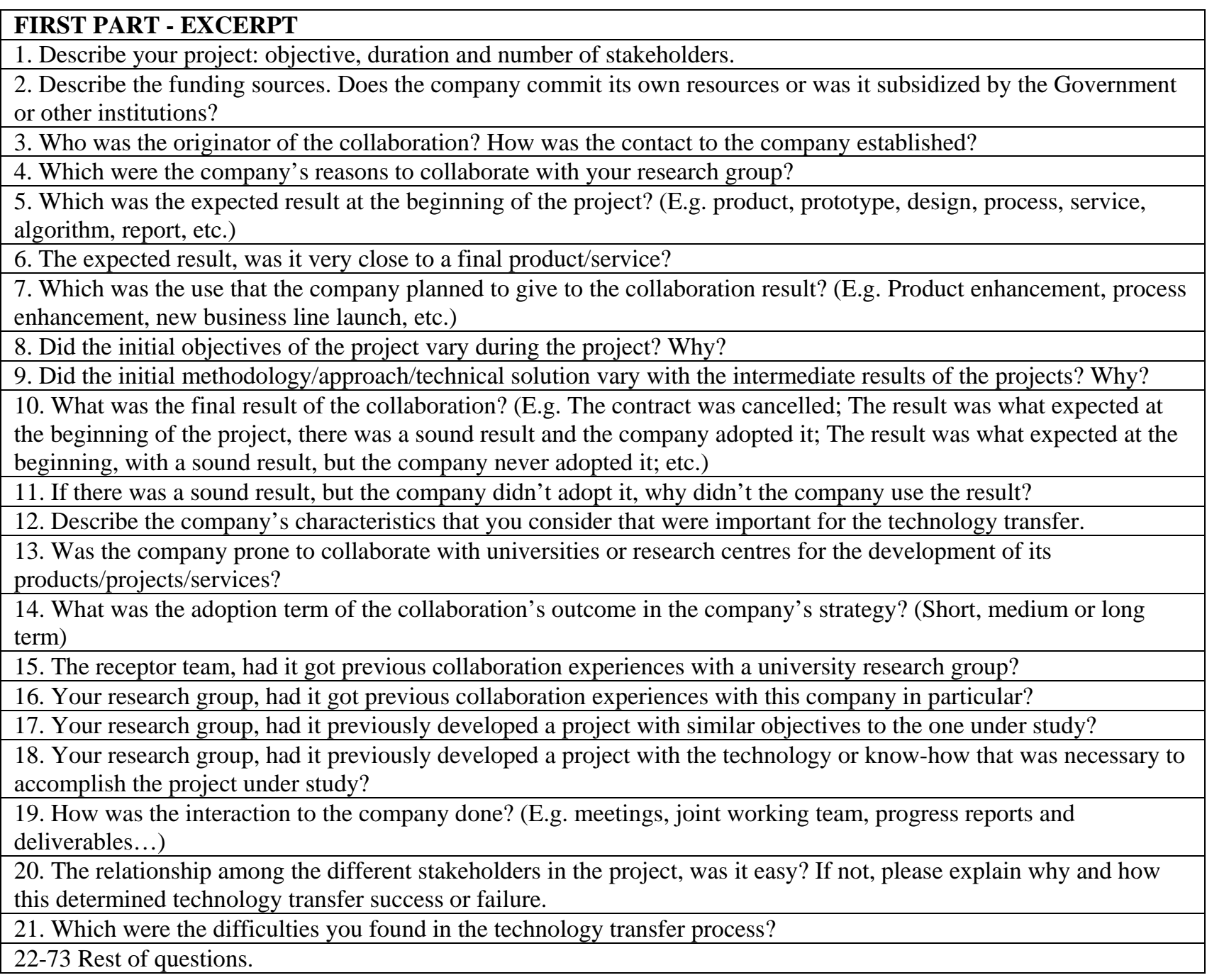

